\title{
PRODUÇÃO DE EQUINENONA A PARTIR DO CULTIVO HETEROTRÓFICO DE MICROALGA PHORMIDIUM sp
}

\author{
S. R. KACHUK-SILVA ${ }^{1}$, D. B. RODRIGUES ${ }^{1}$, A. S. FERNANDES, ${ }^{1}$ A B. SANTOS ${ }^{1}$, E. \\ JACOB-LOPES $^{1}$, L.Q. ZEPKA ${ }^{1}$ \\ ${ }^{1}$ Universidade Federal de Santa Maria, Departamento Tecnologia e Ciência dos Alimentos \\ E-mail para contato: lqz@pq.cnpq.br
}

\begin{abstract}
RESUMO - Microalgas são importantes fontes comerciais para a produção de produtos químicos de alto valor agregado, como os carotenoides. O objetivo do trabalho foi investigar a produção de equinenona a partir da microalga Phormidium sp. em cultivo heterotrófico. A biomassa foi obtida através do cultivo heterotrófico, em reator de coluna de bolhas operando em regime de batelada utilizando 2 litros de água residuária como meio de cultura. A extração dos carotenoides da biomassa foi feita por ultrassom com sonda de $13 \mathrm{~mm}$, e a identificação dos compostos por cromatografia líquida de alta eficiência com detector de arranjo de diodos, compostos por cromatografia de padrões idênticos. Os resultados demonstraram que as condições de produção de biomassa, visando uma escala industrial de $10.000 \mathrm{~m}^{3} / \mathrm{d}$, podem ser estabelecidas permitindo uma produção de $12.728,9 \mathrm{~kg}^{-\mathrm{ano}^{-1}}$ de all-trans-equinenona e $9.991,9 \mathrm{~kg} \cdot \mathrm{ano}^{-1}$ de cisquinenona.
\end{abstract}

\section{INTRODUÇÃO}

Microalgas são consideradas fontes comerciais para a produção de uma grande diversidade de biomoléculas, apresentando inúmeras vantagens quando comparado a matérias primas convencionais, tais como, a disponibilidade de cultivo em terras não aráveis, à possibilidade de crescimento em águas residuais e a versatilidade de modificação de composição bioquímica em função das condições de cultivo (Olaizola, 2003; Li et al, 2007; Sheehan et al, 1998; Stephenson et al, 2010).

As microalgas quando submetidas a modificações nas condições de cultivo, sofrem aumento na produção de alguns compostos de interesse, como os carotenoides (Aflalo et al, 2007; García-Malea et al, 2009; Shahid et al, 2013). Industrialmente, carotenoides como a astaxantina são responsáveis pela coloração vermelha de muitos animais marinhos, como o salmão (Chien e Shiau, 2005). Estima-se que $15 \%$ do custo da produção de salmão está relacionado com a utilização da astaxantina, o que limita economicamente esta cadeia produtiva (Mann, et al., 2000). Nesse sentido, pesquisas vem sendo realizadas na busca de fontes alternativas para produção de cetocarotenoides (Misawa, 2009; Zhu et al, 2009).

Cetocarotenoides como a equinenona e a cataxantina que apresentam cromóforo com números superior de ligações duplas conjugadas que o all-trans- $\beta$-caroteno e característica 


\section{9 a 22 de outubro de 2014 \\ Florianópolis/SC}

estrutural semelhante a astaxantina são carotenoides majoritários em biomassa microalgal e apresentam um apelo econômico promissor (Albrecht et al, 2000; Klassen; Foght, 2011). As microalgas possuem uma ampla versatilidade metabólica o que contribui para a habilidade de sintetizar carotenoides em quantidades consideráveis com estruturas químicas diferenciadas (Albrecht et al, 2000; Mandelli et al, 2012). Em face disso, este trabalho tem por objetivo a avaliação do potencial da produção natural de equinenona a partir da microalga Phormidium sp. em cultivo heterotrófico de águas residuárias.

\section{MATERIAL E MÉTODOS}

\subsection{Microrganismos e meios de cultura}

Culturas de Phormidium sp. foram originalmente isoladas do deserto Cuatro Cienegas no México $\left(26^{\circ} 59^{\prime} \mathrm{N} 102^{\circ} 03 \mathrm{~W}\right)$. As culturas de reserva foram propagadas e mantidas em solidificado de agar-agar (20 g. $\mathrm{l}^{-1}$ ) contendo meio BGN sintético (Rippka et al, 1979). As condições de incubação usadas foram de $25^{\circ} \mathrm{C}$, uma densidade de fluxo de fótons de $15 \mu \mathrm{molm}^{-2} \mathrm{~s}^{-1}$ e foto período de 12 horas de luz/escuro.

\subsection{Produção de biomassa de microalgas}

A produção de biomassa foi realizada em condições heterotróficas. As culturas foram realizadas em um biorreator (Francisco et al, 2014), operando em regime de batelada utilizando 2,0 L de água residuária como meio de cultura. As condições experimentais foram as seguintes: concentração inicial do inóculo de $100 \mathrm{mg} .1^{-1}$, temperatura de $26{ }^{\circ} \mathrm{C}$, pH 7,6, razão de carbono/nitrogênio de 30 (ajustado com glicose), na ausência de luz e tempo de residência de 168 horas. A biomassa foi separada do efluente por centrifugação e liofilizada. Os cultivos foram realizados em duplicata.

\subsection{Métodos analíticos}

Extração de carotenoides. Os carotenóides foram extraídos por ultrassom (UAE) utilizando um processador ultra-sônico (Sonics, Anaheim, CA, EUA) com uma sonda de $13 \mathrm{~mm}$ de diâmetro. As amostras secas $(2 \pm 0,2 \mathrm{~g})$ foram colocadas em um recipiente revestido, através do qual a água foi circulada a $20^{\circ} \mathrm{C}$. As extrações foram realizadas com acetona fria durante 20 minutos e a amplitude da aplicação de extração foi ajustado em $61 \mu \mathrm{m}$. As amostras foram processadas em uma frequência constante de $20 \mathrm{kHz}$. A sonda do ultra-som foi submersa a uma profundidade de $25 \mathrm{~mm}$ na amostra. A suspensão da amostra foi centrifugada durante $10 \mathrm{~min}$ a $3000 \mathrm{rpm}$. O procedimento de extração foi repetido até o sobrenadante se tornar incolor. Os carotenóides foram transferidos para uma mistura de éter de petróleo/éter dietílico [1:1 (v/v)], e saponificado por $12 \mathrm{~h}$ com $10 \%(\mathrm{~m} / \mathrm{v})$ de hidróxido de potássio $(\mathrm{KOH})$ em metanol, à temperatura ambiente $\left(25^{\circ} \mathrm{C}\right)$. $\mathrm{O}$ meio alcalino foi removido por lavagem do extrato com água destilada e o extrato concentrado em evaporador rotativo $\left(\mathrm{T}<30^{\circ} \mathrm{C}\right)$ e posteriormente armazenado em atmosfera saturada de nitrogênio até o momento da análise cromatográfica. 
Análise HPLC-DAD-MS/MS. Os carotenóides foram analisados por cromatografia líquida de alta eficiência HPLC (Shimadzu, Kyoto, Japão) equipado com bombas quaternárias (modelo LC-20AD), desgaseificador em linha, e válvula de injeção com um loop de $20 \mu \mathrm{L}$ (Rheodyne, Rohnert Park- CA, EUA). O equipamento foi ligado em série a um detector de PDA (modelo SPD-M20A) e um espectrômetro de massas com um analisador de "íon trap" com ionização química a pressão atmosférica (APCI) (modelo Esquire 4000, Bruker Daltonics, Bremem, Alemanha). Os espectros de UV-visível foram obtidos entre 250 e $600 \mathrm{~nm}$, e os cromatogramas foram processados a $451 \mathrm{~nm}$. Os parâmetros de MS foram definidos de acordo com Zepka e Mercadante, 2009. A separação dos carotenóides foi realizada em uma coluna C30 YMC (5 $\mu \mathrm{m}, 250$ x $4.6 \mathrm{~mm}$ id) (Waters, Wilmington, DE, EUA ).

A identificação foi realizada em função da ordem de eluição na coluna C30, cocromatografia com padrões, as características de espectro UV-visível [comprimento de onda de absorção máxima ( $\lambda$ máx), estrutura fina espectral (\% III/II) e cis pico intensidade (\% AB/AI)] e as características dos espectros de massa (moléculas protonadas e os seus fragmentos MS/MS). Estes resultados foram comparados com a literatura (Britton, Liaaen-Jensen e Pfander, 2004; De Rosso e Mercadante, 2007; Zepka e Mercadante, 2009; Van Breemen et al, 2012).

Os carotenoides foram quantificados usando curvas analíticas de cinco pontos com padrão de all-trans- $\beta$-caroteno (1.1-30.2 $\left.\mu \mathrm{g} \cdot \mathrm{ml}^{-1}\right)$.

\section{RESULTADOS E DISCUSSÃO}

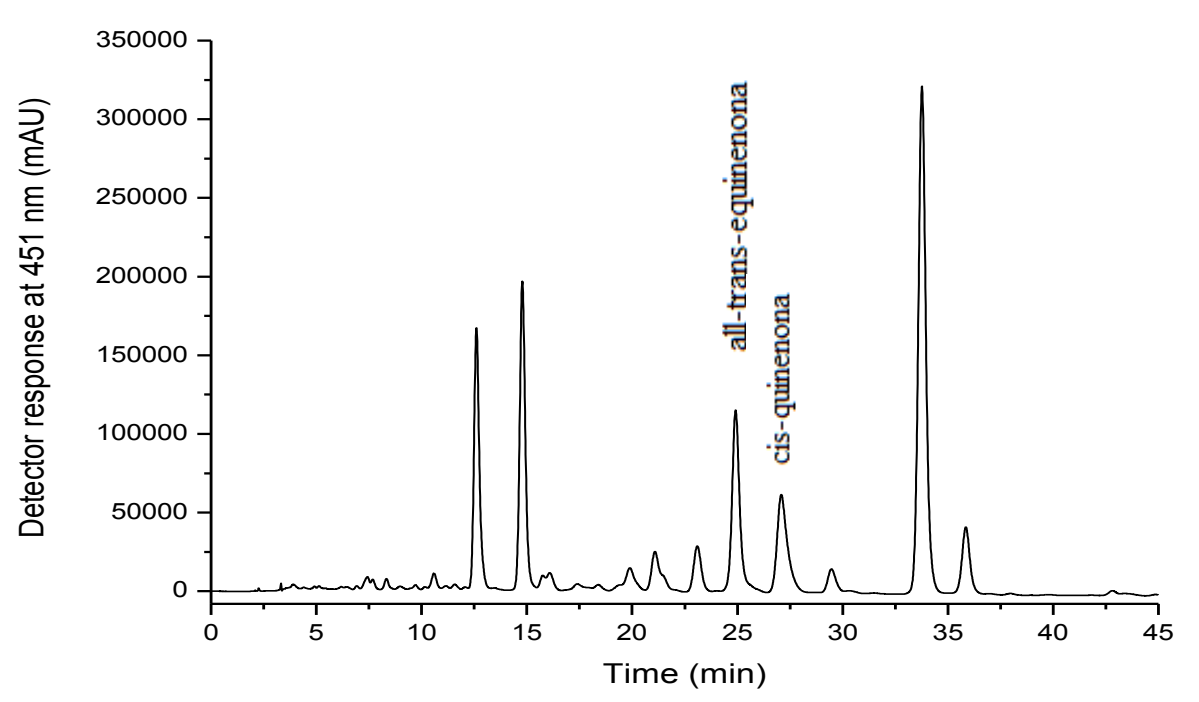

Figura 1. Cromatograma do extrato de carotenoides da biomassa.

Na Figura 1 pode se observar a separação de vinte carotenoides, sendo identificados a alltrans-equinenona e cis-equinenona com base na informação obtida na coluna C30. Os 
carotenoides all-trans-equinenona e cis-quinenona apresentaram o mesmo padrão de fragmentação de massas. Considerando as características do espectro UV-Vis o isômero alltrans-equinenona exibiu estrutura fina correspondente a presença de um grupo carbonila (463 $\mathrm{nm}$ ), o espectro UV-Vis da cis-quinenona corresponde a um deslocamento hipsocromo de $9 \mathrm{~nm}$ $(452 \mathrm{~nm})$ e o aparecimento de um pico cis $(344 \mathrm{~nm})$ quando comparado com a conformação alltrans. Os espectros de massas de ambas estruturas obtidas no modo íon positivo forneceram moléculas protonada de M/Z 559 e fragmentação MS/MS de M/Z 553 [M+H-18] $]^{+}$e M/Z 459 $[\mathrm{M}+\mathrm{H}-92]^{+}$que correspondem a perda de uma molécula de água e de um grupamento de tolueno a partir da cadeia poliênica (Tabela 1)

Tabela 1. Características cromatográficas, UV-Vis e de espectro de massas obtidas por HPLCPDA-MS/MS do extrato de carotenoides da biomassa Phormidium sp.

\begin{tabular}{|c|c|c|c|c|c|c|}
\hline \multirow{2}{*}{ Carotenoides } & \multirow[b]{2}{*}{$\begin{array}{c}\mathbf{t}_{\mathbf{R}} \\
(\min )^{\mathrm{a}}\end{array}$} & \multicolumn{2}{|c|}{ UV-Vis características } & \multicolumn{2}{|c|}{$\begin{array}{l}\text { Fragmentos ions (modo positivo) } \\
(\mathrm{m} / \mathrm{z})\end{array}$} & \multirow{2}{*}{$\begin{array}{c}\text { Conteúdos } \\
\text { de } \\
\text { Carotenoides } \\
\left(\mu \mathrm{g} . \mathrm{g}^{-1}\right)^{\mathrm{d}}\end{array}$} \\
\hline & & $\begin{array}{c}\lambda_{\text {máx }} \\
(\mathbf{n m})^{b}\end{array}$ & $\mathrm{AB} / \mathrm{II}(\%)^{\mathrm{c}}$ & {$[\mathbf{M}+\mathbf{H}]^{+}$} & MS/MS & \\
\hline $\begin{array}{l}\text { All-trans- } \\
\text { equinenona }\end{array}$ & 24.9 & 463 & 0 & 551 & $\begin{array}{l}533[\mathrm{M}+\mathrm{H}-18]^{+}, 495 \\
459[\mathrm{M}+\mathrm{H}-92]^{+}, 203\end{array}$ & $19.87 \pm 0.9$ \\
\hline Cis-equinenona & 27.1 & 344,452 & 19 & 551 & $\begin{array}{l}533[\mathrm{M}+\mathrm{H}-18]^{+}, 495 \\
459[\mathrm{M}+\mathrm{H}-92]^{+}, 203\end{array}$ & $15.70 \pm 0.1$ \\
\hline
\end{tabular}

aTr: Tempo de retenção na coluna C30.

${ }^{b}$ gradiente linear de metanol:TBME

${ }^{c}$ razao entre o pico cis e o pico II

${ }^{d} n=3$

Através do balanço de massa, foram realizadas estimativas teóricas do aumento de escala do processo, considerando em diferentes escalas industriais. Conforme o tamanho da planta foi estimado a produção de biomassa de $5.690,56.902$ e 56.9016 ton $_{\text {biomassaano }}{ }^{-1}$ numa pequena $\left(100 \mathrm{~m}^{3} \cdot \mathrm{d}^{-1}\right)$, média $\left(1.000 \mathrm{~m}^{3} \cdot \mathrm{d}^{-1}\right)$ e grande $\left(10.000 \mathrm{~m}^{3} \cdot \mathrm{d}^{-1}\right)$ indústria respectivamente, resultando numa produção total de carotenóides de $107.902,5 \mathrm{~kg} \cdot \mathrm{ano}^{-1}$. No que se refere a produção de alltrans-equinenona nas mesmas condições citadas acima estimou-se 127,3, 1.272,9 e 12.728,9 kg. ano ${ }^{-1}$ enquanto seu isômero cis-quinenona 99,9, 999,2 e 9.991,9 kg.ano-1 respectivamente. O interesse na produção de carotenoides a partir de microalgas deve-se ao fato destes pigmentos apresentarem relevante importância comercial. Como estes pigmentos são sintetizados biotecnologicamente, a produção, é considerada renovável com elevado potencial de aplicabilidade econômica (Armstrong et al, 1997; Mendonça et al, 2012). 


\section{CONCLUSÃO}

A partir dos resultados obtidos, verifica-se o potencial de aplicação destas rotas tecnológicas para a produção em escala industrial de equinenona na conformação trans e cis por Phormidium sp. cultivada em efluentes agroindustriais.

\section{REFERÊNCIA}

ALBRECHT, M. et al. Novel hydroxycarotenoids with improved antioxidative properties produced by gene combination in Escherichia coli. Nature Biotechnology, 18, 843-846, 2000.

AFLALO, C., MESHULAM, Y., ZARKA, A., BOUSSIBA, S. On the relative efficiency of twovs. one-stage production of astaxanthin by the green alga Haematococcus pluvialis. Biotechnol. Bioenerg., 98, 300-305, 2007.

ARMSTRONG, G.A. Genetics of eubacterial carotenoid biosynthesis, a colourful tale. Annu. Rev. Microbiol., 51, 629-659, 1997.

BRITTON, G., LIAAEN-JENSEN, S., PFANDER, H. (EDS.). Carotenoids: handbook. Birkhäuser Verlag, Badel, 2004.

CHIEN, Y.H., SHIAU, W.C. The effects of dietary supplementation of algae and synthetic astaxanthin on body astaxanthin, survival, growth, and low dissolved oxygen stress resistance of kuruma prawn, Marsupenaeus japonicas Bate. J.Exp. Mar.Biol.Ecol., 318, 201-211, 2005.

DE ROSSO, V.V., MERCADANTE, A.Z. Identification and quantification of carotenoids, by HPLC-PDA-MS/MS, from Amazonian fruits. J. Agric. Food Chem., 55, 5062-5072, 2007.

FRANCISCO, E. C.; FRANCO, T. T.; WAGNER, R.; JACOB-LOPES, E. Assessment of different carbohydrates as exogenous carbon source in cultivation of cyanobacteria. Bioprocess and Biosystems Engineering, 36, 1986-1995, 2014.

GARCÍA-MALEA, M.C., ACIÉN, F.G., DEL RÍO, E., FERNÁNDEZ, J.M., CERÓN, M.C., GUERRERO, M.G., ET AL. Production of astaxanthin by Haematococcus pluvialis: taking the onestep system outdoors. Biotechnol. Bioeng., 102, 651-657, 2009.

LI, X., XU, H.,WU, Q. Large-scale biodiesel production from microalga Chlorella protothecoides through heterotrophic cultivation in bioreactors. Biotechnol. Bioeng., 98, 764-771, 2007.

KLASSEN, J. L.; FOGHT, J. M. Characterization of hymenobacter isolates from Victoria Upper Glacier, Antarctica reveals five new species and substantial non-vertical evolution within this genus. Extremophiles, 15, 45-57, 2011. 
MANDELLI, F., MIRANDA, V.S., RODRIGUES, E., MERCADANTE, A.Z. Identification of carotenoids with high antioxidant capacity produced by extremophile microorganisms. World $J$. Microb. Biot., 28, 1781-1790, 2012.

MENDONÇA, T. A.; DRUZIAN, I. J.; NUNES, I. L. Prospecção tecnológica da utilização da Spirulina platensis. Cadernos de Prospecção Tecnológica, 5, 44-52, 2012.

MISAWA, N. Pathway engineering of plants to ward astaxanthin production. Plant Biotechnol., 26, 93-99, 2009.

OLAIZOLA, M. Commercial development of microalgal biotechnology: from the test tube to the marketplace. Biomol. Eng., 20, 459-466, 2003.

RIPPKA, R., DERUELLES, J., WATERBURY, J.B., HERDMAN, M., STANIER, R.Y. Generic assignments, strain histories and properties of pure cultures of cyanobacteria. J. Gen. Microbiol., $111,1-61,1979$.

SHAHID, M., SHAHID-UL-ISLAM, MOHAMMAD, F. Recent advancements in natural dye applications: a review. J. Clean. Prod., 53, 310-331, 2013.

SHEEHAN, J., DUNAHAY, T., BENEMANN, J., ROESSLER, P. A Look Back at the U.S. Department of Energy's Aquatic Species Program: Biodiesel from Algae. NREL/TP-580-24190. U.S. Department of Energy, Washington D.C. (United States), 1998.

STEPHENSON, A.L., KAZAMIA, E., DENNIS, J.S., HOWE, C.J., SCOTT, S.A., SMITH, A.G. Life-cycle assessment of potential algal biodiesel production in the United Kingdom: A comparison of raceways and air-lift tubular bioreactors. Energy Fuels, 24, 4062-4077, 2010.

VAN BREEMEN, R.B., DONG, L., PAJKOVIC, N.D. Atmospheric pressure chemical ionization tandem mass spectrometry of carotenoids. Int. J. Mass Spectrom., 312, 163-172, 2012.

ZEPKA, L. Q., \& MERCADANTE, A. Z. Degradation compounds of carotenoids formed during heating of a simulated cashew apple juice. Food Chemistry, 117, 28-34, 2009.

ZHU, C., NAQVI, S., CAPELL, T., CRISTOU, P. Metabolic engineering of ketocar- otenoid biosynthesis in higher plants. Arch.Biochem.Biophys.483,182- 190, 2009. 